\title{
Efektivitas Konseling Realita Terhadap Rasa Rendah Diri Pada Siswa Kelas X Sekolah Menengah Atas Negeri 1 Surabaya
}

\author{
Aniek Wirastania \\ Universitas PGRI Adi Buana Surabaya \\ Email: aniek@unipasby.ac.id
}

\begin{abstract}
Low self-esteem is a form of attitude that arises from the feeling of someone who feels himself feeling inadequate when compared with the condition of others and this condition continues with feelings that result in negative attitudes of the individual can even make self-judgment. The high level of low self-esteem owned by a student will be able to have a negative influence, especially in learning activities at school. A service that is considered to be able to overcome the problem of high self-esteem is to use reality counseling techniques. This study aims to look at the effectiveness of reality counseling techniques in reducing students' inferiority complex. This research is a quasi-experimental study with the research design used is non-equivalent pretest-posttest one group design. Reality counseling technique is carried out in this counseling is to use the WDEP system development. The WDEP system that is carried out at each reality counseling session is done through a strategy that consists of wants and needs, namely wants and needs, direction and doing, namely direction and action, self evaluation, which is evaluation carried out on oneself, and the last is planning, which is plan continue on what action will be taken. The treatment that was done by using reality group technical counseling was considered effective in reducing the sense of inferiority and developing the successful identity of each student. This study shows the results that there are differences in the level of low self-esteem of students before and after following the reality engineering counseling session. Reality counseling techniques are effective in reducing the level of low self-esteem of students.
\end{abstract}

Keywords: Low self-esteem, Counseling, Reality Techniques, Quasi Experiment

\section{Open Access Received : 2020-01-21 Published : 2020-01-30.}

This is an open access article distributed under the terms of the Creative Commons Attribution 4.0 International License

Website: http://ejournal.umpri.ac.id/index.php/fokus

\section{A. PENDAHULUAN}

Rasa rendah diri menurut Sadarjoen (2008) merupakan sebuah perasaan dimana seorang individu merasa kekurangan saat dibandingkan dengan orang lain berdasarkan karena kesadaran ras tertentu, memiliki kekurangan fisik, pendidikan, kemiskinan serta keturunan yang tidak baik di lingkungan masyarakat. Perasaan ini muncul ketika terjadi suatu peristiwa dan merupakan hasil imajinasinya. Pernyataan ini sependapat dengan Adler (dalam Corey, 2005) yang menyatakan bahwa rasa rendah diri adalah suatu perasaan seorang individu dimana dirinya merasa lebih rendah daripada orang lain, perasaan yang dirasakan individu muncul dari satu peristiwa yang nyata dan imajinasinya sendiri. 
Rendah diri merupakan sebuah bentuk sikap yang timbul dari perasaan seseorang yang merasa dirinya merasa serba kekurangan bila dibandingkan dengan kondisi orang lain dan kondisi ini berlanjut dengan perasaan-perasaan yang berakibat menimbulkan sikap-sikap negatif dari individu bahkan bisa membuat menghakimi diri sendiri. Sedangkan Menurut Hadiwidjoyo (2018) rasa rendah diri adalah suatu perasaan yang membuat seorang individu merasa bahwa dirinya memiliki banyak kurang saat dibandingkan dengan orang lain. Saat kita melihat bahwasanya rendah diri sepertinya bukanlah suatu masalah yang berat bagi seorang individu, namun rasa rendah diri apabila tidak mendapatkan penanganan yang baik akan dapat memberikan dampak yang buruk bagi individu. Salah satu hal yang perlu diperhatikan hanya karena perasaan rendah diri ini dapat membuat seseorang melakukan bunuh diri. Tingginya tingkat rendah diri yang dimiliki seorang siswa akan dapat memberikan pengaruh negatif terutama dalam kegiatan belajar di sekolah.

Menurut Hadiwidjoyo (2018) rasa rendah diri ini muncul dikarenakan beberapa hal yang terjadi baik dari dalam diri individu serta lingkungan sekitarnya. Berikut ini hal-hal yang dapat menimbulkan rasa rendah diri yaitu sebagai berikut; a) saat individu merasa dirinya terabaikan; b) ketika individu mendapatkan kritikan yang berlebihan dari orang-orang sekitarnya; c)pengaruh dari keluarga, dimana kondisi ini terjadi ketika orang tua yang selalu mengatur segala hal yang harus dilakukan oleh anaknya; serta d) individu merasa selalu kekurangan dalam dirinya, biasanya hal ini terjadi karena pengaruh lingkungan dan hubungan sosial dengan teman-teman sebayanya. Permasalahan rasa rendah diri siswa ini dapat diatasi dengan menggunakan salah satu layanan dalam bimbingan dan konseling yang dinilai efektif dalam mengurangi masalah siswa serta meningkatkan kepercayaan diri siswa.

Permasalahan rendah diri pada siswa harus segera diselesaikan, salah satu usaha yang dapat dilakukan dalam mengatasi permasalahan ini adalah dengan menggunakan layanan Bimbingan dan konseling yang memiliki peranan penting dalam dunia pendidikan. Bimbingan dan konseling bertanggung jawab dalam memberikan pendampingan serta memfasilitasi perkembangan siswa supaya memiliki sikap yang mandiri, serta mampu membuat keputusan, bertanggung jawab terhadap segala tindakan yang dilakukan ketika menyelesaikan masalahnya agar menjadi manusia yang memiliki budaya, produktif, serta dapat memiliki perkembangan optimal. Kondisi ini sesuai dengan pendapat Yusuf (2009) yang menyatakan bahwa konseling adalah bantuan yang diberikan oleh seorang konselor pada konselinya yang pelaksanaannya dilakukan secara bertatap muka serta menggunakan media yang memiliki tujuan agar dapat mengembangkan potensi dirinya melalui pemecahan masalah agar dapat mengembangkan dirinya menjadi pribadi yang bernilai baik bagi dirinya maupun orang lain. Selain itu Willis (2007) menyatakan bahwa konseling merupakan suatu usaha bantuan yang diberikan oleh pembimbing terlatih dan berpengalaman dalam menghadapi individu yang memiliki masalah dimana layanan ini memiliki tujuan agar konseli dapat mengembangkan potensi yang dimiliki dengan optimal, beradaptasi dengan kondisi lingkungan sekitar, serta mengatasi permasalahan yang dihadapinya dalam kehidupan. 
Semua orang memiliki hak yang sama dalam mendapatkan layanan bimbingan dan konseling. Siswa Sekolah Menengah Atas memiliki hak dalam menggunakan layanan bimbingan dan konseling untuk membantu mereka mengatasi permasalahan yang dihadapi serta menuju pengembangan diri secara optimal. Berhubungan dengan permasalahan untuk mengurangi tingkat rasa rendah diri siswa maka layanan yang dipandang dapat mengatasi adalah dengan menggunakan teknik konseling realita Menurut Latipun (2005) teknik konseling realita memiliki tujuan umum agar seorang konseli dapat mengubah dirinya menjadi identitas diri yang sukses, dimana kesuksesan identitas ini ditandai dengan pemahaman adanya nilai-nilai positif yang dimiliki seorang individu.

Teknik konseling realita berfokus pada tanggung jawab seorang konseli, agar dirinya dapat memiliki sikap dan perilaku sesuai dengan kenyataan yang dihadapi saat ini. Permasalahan yang dihadapi konseli saat ini terjadi karena kurangnya kesadaran tanggung jawab dalam berperilaku sehingga mengakibatkan terjadinya gangguan dalam kesehatan mentalnya. Menurut Glasser (Winkel, 2007) seorang individu yang memiliki mental sehat harus dapat menunjukkan tanggung jawab pada perilakunya serta memiliki cara yang benar dalam berperilaku. Teknik konseling realita memiliki asumsi sebuah realisasi untuk berkembang sebagai usaha untuk memberikan kepuasan kebutuhan harus berlandaskan pada prinsip 3R yang terdiri atas: right yang bermakna melakukan pembelajaran yang benar, responsibility yang berarti berperilaku dan dapat mempertanggungjawabkannya, serta reality yang bermakna dapat menghadapi sebuah kenyataan.

Teknik konseling realita ini dilakukan dengan menggunakan pengembangan sistem WDEP. Pengembangan sistem WDEP dalam konseling realita ini menurut Wubboding (Corey, 2013) adalah sebuah kumpulan strategi yang terdiri atas wants and needs yaitu keinginan dan kebutuhan, direction and doing yaitu arah dan tindakan, self evaluation yaitu evaluasi yang dilakukan pada diri sendiri, serta yang terakhir adalah planning yaitu rencana yang berlanjut pada tindakan apa yang akan dilakukan.

\section{METODE}

Pendekatan kuantitatif digunakan dalam penelitian ini. Penggunaan Pendekatan kuantitatif dalam penelitian ini dikarenakan penelitian ini melakukan kegiatan mencatat, serta melakukan uji analisis data secara eksak menggunakan uji statistik tentang efektifitas konseling realita terhadap rasa rendah diri pada siswa yang dinilai dalam bentuk angka. Teknik ini dilakukan sebagai cara dalam mempermudah analisis data serta menjelaskan hasil penelitiannya. Metode yang digunakan dalam penelitian ini adalah quasi eksperimen, Desain penelitian yang digunakan adalah Pretest Posttest One Group Design. Sampel penelitian ini sejumlah 6 siswa yang dipilih melalui teknik purposive sampling dari populasi sejumlah 35 siswa. Penelitian ini menggunakan instrumen angket rendah diri untuk pengumpulan data tingkat rendah diri pada siswa kelas X di SMA Negeri 1 Surabaya. 


\section{HASIL DAN PEMBAHASAN}

Observasi yang dilakukan pada awal kegiatan penelitian menunjukkan sebuah kondisi bahwa tingkat rasa rendah diri pada siswa kelas X di SMA Negeri 1 Surabaya mayoritas pada tingkat sedang. Hasil kegiatan observasi juga menunjukkan bahwa kondisi tingkat rasa rendah diri pada siswa kelas X di SMA Negeri 1 beraneka ragam. Kondisi ini bermakna bahwa rasa rendah diri ini didasari oleh berbagai macam kondisi keberagaman siswa yang berasal dari diri sendiri, keluarga, serta lingkungan yang memberikan pengaruh dalam kehidupan seorang individu.

Penemuan beberapa fakta dari kegiatan observasi menunjukkan bahwa kondisi keberagaman siswa dapat meningkatkan rasa rendah diri siswa, kondisi yang paling memberikan pengaruh kuat sehingga mengakibatkan tingginya rasa rendah diri siswa adalah dari lingkungan sekitar yang dapat dilihat dari keberagaman suku dan budaya dari teman-teman sebaya, tingkat ekonomi yang memberikan pengaruh pada gaya hidup seorang individu. Kondisi yang nampak ini hanya dapat diatasi dengan melakukan perubahan diri konseli agar dapat menjadi indvidu yang memiliki identitas sukses dimana hal ini dapat dilihat ketika konseli telah dapat menemukan nilai-nilai positif yang ada dalam dirinya sehingga dia dapat berperilaku dengan benar sesuai dengan kenyataan hidup yang harus dijalani serta bertanggung jawab.

Layanan Konseling dengan menggunakan teknik realita yang dilaksanakan dalam penelitian ini dilakukan sebagai usaha membantu konseli dalam mengatasi permasalahan yang dihadapi saat ini yaitu tingginya rasa rendah diri pada siswa kelas $\mathrm{X}$ di SMA Negeri 1 Surabaya. Setiap konseli yang memiliki rasa rendah diri tinggi diberikan layanan konseling dengan menggunakan teknik realita secara berkelompok. Layanan konseling ini dilakukan selama 6 kali treatement sesuai dengan jumlah konseli yang memiliki rasa rendah diri tinggi. Pelaksanaan sesi pretest dan posttest dilakukan dengan pengisian angket rendah diri serta melakukan pengamatan secara langsung pada perilaku yang menunjukkan rasa rendah diri siswa. Sesi pretest yang dilaksanakan pada tahap awal mendapatkan sebuah hasil bahwa ada 6 siswa yang memiliki permasalahan rasa rendah diri yang tinggi.

Siswa SMA Negeri 1 Surabaya yang mendapatkan layanan konseling kelompok teknik realita adalah yang memiliki rasa rendah diri tinggi. Tingginya rasa rendah diri ini didapat berdasar pada hasil pengisian angket rasa rendah diri. Siswa yang memiliki tingkat rasa rendah diri tinggi adalah sebagai berikut ini AWK, RAN, DAH, VRA, ERL, dan LHF. Enam siswa ini terindikasi memiliki permasalahan pada tingginya rasa rendah diri dan harus mendapatkan bantuan agar dapat mengatasi permasalahannya. Salah satu layanan yang digunakan dalam membantu siswa dalam mengurangi rasa rendah diri mereka adalah dengan dilakukan konseling secara berkelompok dengan menggunakan teknik konseling realita.

Teknik konseling realita ini dilakukan dalam konseling ini adalah dengan menggunakan pengembangan sistem WDEP. Sistem WDEP yang dilakukan pada setiap sesi konseling realita ini dilakukan melalui strategi yang terdiri atas wants and needs yaitu keinginan dan kebutuhan, direction and doing yaitu arah dan tindakan, self evaluation yaitu evaluasi yang dilakukan pada diri sendiri, serta yang terakhir adalah planning yaitu rencana yang berlanjut pada tindakan apa yang akan dilakukan. Treatmen yang dilakukan dengan menggunakan konseling kelompok teknik realita ini dinilai efektif dalam mengurangi rasa rendah diri dan mengembangkan identitas 
sukses yang dimiliki setiap siswa. Berkurangnya tingkat rasa rendah diri siswa dapat dinilai berdasar pada tabel berikut ini.

Tabel I :perbandingan skor pretest dan post test

\begin{tabular}{cccc}
\hline Responden & Pre test & Post Test & $\begin{array}{c}\text { Tingkat } \\
\text { Perubahan }\end{array}$ \\
\hline AWK & 72 & 55 & 17 \\
\hline RAN & 76 & 58 & 18 \\
\hline DAH & 71 & 58 & 14 \\
\hline VRA & 71 & 60 & 11 \\
\hline ERL & 76 & 69 & 10 \\
\hline LHF & 74 & 69 & 5 \\
\hline
\end{tabular}

Efektifitas teknik konseling realita dapat dilakukan melalui uji komparasi pretest dan posttest subjek penelitian dengan pengujian statistik dengan menggunakan Uji Wilcoxon. Nilai W dinilai melalui pengambilan nilai yang terkecil dari $\mathrm{W}+$ dan $\mathrm{W}-$. Kriteria pengujian menggunakan dasar penerimaan $\mathrm{H}_{\circ}$ jika $\mu \mathrm{A}-\mu \mathrm{B}=0$ atau tolak $\mathrm{H}_{\mathrm{o}}$ dan terima $\mathrm{H}_{1}$ jika $\mu \mathrm{A}-\mu \mathrm{B} \neq 0$, hanya jika $\mathrm{W}+$ dan $\mathrm{W}$ - cukup kecil. Perhitungan ini dilakukan dengan menggunakan program SPSS for Windows versi 17.

Pengujian statistik diperoleh asymp Sig $=0,28$, nilai Asymp. Sig. $=0.001<\alpha=$ 0.05 maka $\mathrm{H}_{\circ}$ ditolak dan $\mathrm{H}_{1}$ diterima. Artinya, terdapat perbedaan skor rasa rendah diri siswa antara sebelum mengikuti konseling realita dengan setelah menjalani konseling realita. Berdasarkan hasil pengujian statistik di atas, maka penelitian ini menunjukkan bahwa layanan konseling realita efektif dalam mengatasi rasa rendah diri pada siswa tingkat sekolah menengah atas.

Penelitian yang telah dilaksanakan pada siswa kelas X di SMA Negeri 1 Surabaya ini menunjukkan hasil bahwa konseling realita efektif dalam mengatasi permasalahan rendah diri yang dimiliki oleh beberapa siswa. Keefektifan penggunaan teknik konseling realita ini sesuai dengan pendapat Humaira (2018) yang menyatakan bahwa konseling realita dapat membantu para konseli dalam menghadapi permasalahan yang membuat konseli memiliki rasa rendah diri dimana permasalahan tersebut disebabkan karena adanya sebuah kondisi yang menguncang kondisinya secara psikologis. Permasalahan rendah diri harus dapat segera diselesaikan agar tidak memberikan pengaruh pada perilaku dalam kehidupan bermasayarakat.

Kondisi ini sesuai dengan pendapat Wubbolding (Corey , 2013) yang menyatakan konseling realita yang dilakukan dengan menggunakan sistem WDEP dapat efektif dalam mengatasi permasalahan yang dihadapi oleh siswa. Kondisi ini dikarenakan pada setiap huruf dalam strategi WDEP dalam konseling realita memiliki strategi khusus, yaitu sebagai berikut ini $\mathrm{W}=$ wants \& needs yaitu keinginan dan kebutuhan dari seorang individu, $\mathrm{D}=$ direction \& doing yang memiliki makna arah serta tindakan apa yang dilakukan, $\mathrm{E}$ = evaluation yang bermakna setiap selesai melaksanakan suatu 
tindakan harus dilakukan kegiatan evaluasi, dan yang terakhir adalah $\mathrm{P}=$ planning yang bermakna sebuah perencanaan yang akan dilakukan di masa yang akan datang.

\section{KESIMPULAN}

Penelitian dilakukan pada siswa kelas X di SMA Negeri 1 Surabaya. Secara umum para siswa memiliki tingkat rasa rendah diri sedang. Hasil kegiatan observasi juga menunjukkan bahwa kondisi tingkat rasa rendah diri pada siswa kelas X di SMA Negeri 1 beraneka ragam. Kondisi ini bermakna bahwa rasa rendah diri ini didasari oleh berbagai macam kondisi keberagaman siswa yang berasal dari diri sendiri, keluarga, serta lingkungan yang memberikan pengaruh dalam kehidupan seorang individu. Layanan Konseling teknik realita yang dilaksanakan dalam penelitian ini dilakukan sebagai usaha membantu konseli dalam mengatasi permasalahan yang dihadapi saat ini yaitu tingginya rasa rendah diri pada siswa kelas X di SMA Negeri 1 Surabaya. Setiap konseli yang memiliki rasa rendah diri tinggi diberikan layanan konseling dengan menggunakan teknik realita secara berkelompok. Layanan konseling ini dilakukan selama 6 kali treatement sesuai dengan jumlah konseli yang memiliki rasa rendah diri tinggi. Pelaksanaan sesi pretest dan posttest dilakukan dengan pengisian angket rendah diri serta melakukan pengamatan secara langsung pada perilaku yang menunjukkan rasa rendah diri siswa. Sesi pretest yang dilaksanakan pada tahap awal mendapatkan sebuah hasil bahwa ada 6 siswa yang memiliki permasalahan rasa rendah diri yang tinggi. Teknik konseling realita ini dilakukan dalam konseling ini adalah dengan menggunakan pengembangan sistem WDEP. Sistem WDEP yang dilakukan pada setiap sesi konseling realita ini dilakukan melalui strategi yang terdiri atas wants and needs yaitu keinginan dan kebutuhan, direction and doing yaitu arah dan tindakan, self evaluation yaitu evaluasi yang dilakukan pada diri sendiri, serta yang terakhir adalah planning yaitu rencana yang berlanjut pada tindakan apa yang akan dilakukan. Treatmen yang dilakukan dengan menggunakan konseling kelompok teknik realita ini dinilai efektif dalam mengurangi rasa rendah diri dan mengembangkan identitas sukses yang dimiliki setiap siswa. Sebagai pengembangan dari hasil penelitian ini, diharapkan bagi peneliti selanjutnya dapat melakukan kajian teoritis lebih dalam lagi serta memberikan contoh implementasi pendekatan konseling realita dalam mengatasi berbagai macam masalah yang terjadi di sekitar lingkungan masyarakat.

\section{DAFTAR PUSTAKA}

Corey, G. 2013. Theory and Practice Of Counseling and Psychotherapy. Seventh Edition. Belmont: Brooks/ Cole Thompson Learning.

Hadiwidjoyo, K Vera. 2018. Lima Hal yang Sebabkan Anak Jadi Rendah Diri. Kumparan: Edisi 27 Januari 2018

Humaira. Desy. 2018. Reality Group Counseling to Improve Adolescent Self-Concept From Broken Home Family. Analitika

Latipun. 2006. Psikologi Konseling. Malang . UMM Press 


\section{Aniek Wirastania}

Sadarjoen, S.S. 2008. Standar Pelayanan Psikologi Klinis (SPKK). Himpunan Psikologi Indonesia.

Yusuf, Syamsu. 2009. Program Bimbingan \& Konseling Di Sekolah. Bandung: Rizqi Press

Willis, S Sofyan. 2007. Konseling Individual Teori dan Praktek. Bandung : Alfabeta 